\title{
Examining Project History Narratives: An Analytic Approach
}

\author{
E. J. Davidson \\ College of Business Administration \\ University of Hawaii, Manoa \\ Honolulu, Hawaii 96822, USA \\ Tel: (808) 956-6657 \\ Fax: (808) 956-9889 \\ E-mail:DAVIDSON@busadm.cba.hawaii.edu
}

\begin{abstract}
Scientific interest in human beings' ability and propensity to construe reality through narrative constructions has increased since the 1970s. Although narrative processes have been addressed in the organizational literature, little research attention has yet been given to the role and function of narratives in organizational efforts to develop, implement, and apply information technology. An analytic approach drawn from Mishler (1986b) for the analysis of project history narratives found in research interviews is described. Three project history narratives collected during a field study of systems development are analyzed using this approach. Differences in sensemaking and interpretation revealed in the analysis of each informant's story and comparison of the analysis of multiple stories are discussed. Insights that narrative analysis may provide into the social cognitive worlds of participants in IS development and its applications in IS research are then considered.
\end{abstract}

"I learned that it's unsafe to say anything much about narrative, because if a poststructuralist doesn't get you a deconstructionalist will."

"Some Thoughts on Narrative" by Ursula K. LeGuin, 1980 


\section{INTRODUCTION}

In Actual Minds, Possible Worlds, Bruner (1986) contrasts "two modes of cognitive functioning, two modes of thought, each providing distinctive ways of ordering experience, of constructing reality" (p. 11). Paradigmatic thinking is characterized by the well-formed argument, principled hypothesis, generalized causes, and procedures to empirically test its "truthfulness." Narrative thought, on the other hand, "deals in human or human-like intention and action and the vicissitudes and consequences that mark their course" (p. 13). Its measure is "lifelikeness."

Narrativizing is the interpretive process though which human beings make sense of their experiences by accounting for human actions and intentions in the course of events that occur over time. Human experiences, and memories of them, are typically framed in a narrative form (Bruner 1990). In a narrative, events, actions and accounts of actions move through time and are organized in a way that demonstrates connectedness or coherence to a goal state or end point (Gergen and Gergen 1986). The organization of actions and events accounts for actors' reasons for their acts and implies causes for happenings (Sarbin 1986). Bruner (1990) contends that deviations from canonical cultural patterns are mitigated or made comprehensible in this way, making narratives "especially viable instruments for social negotiations" (p. 55). Narrativizing experience by telling stories is often a collaborative activity between the narrator and listeners, in which the interpretation embodied in a story is tested and adjusted (Boje 1991; Robinson and Hawpe 1986).

Research interest in human beings' ability and propensity to construe reality through narrative constructions has increased since the 1970s in disciplines such as anthropology, linguistics, philosophy, literary theory, and psychology (Howard 1991; Sarbin 1986). Bruner (1990) has characterized scientific interest in narrative as a "renewed cognitive revolution" concerned with interpretation and meaning-making, and Sarbin has proposed narrative as a root metaphor for psychology. Not surprisingly, research interest in narrative processes has extended to the domain of organizational studies. Much of this research has addressed stories as objects which symbolize aspects of organizational culture (Clark 1972; Martin et al. 1983; Martin and Meyerson 1988; Wilkins 1984), internal conflicts (Gabriel 1991; Hansen and Kahnweiler 1993; Mumby 1987), or change efforts (McConkie and Boss 1986). Other researchers have examined the role of storytelling in organizational sensemaking and problem-solving (Boje 1991; Brown and Duguid 1991; Mitroff and Kilmann 1975). More recently, Tenkasi and Boland (1993) have called for empirical research on the day-to-day organizational process of narrativizing experience as a way to examine meaning making and learning in organizations, and Boland and Tenkasi (1995) have posited that narrativizing experience is fundamental to organizational learning and innovation in knowledge-intensive firms.

Despite the growing interest in narrative processes in the organizational literature, little research attention has yet been given to the role and function of narratives in 
organizational efforts to develop, implement, and apply information technology. ${ }^{1}$ Yet these complex social activities, eloquently described here by Bansler and Bødker (1993), require the kind of sensemaking and social negotiations which narrativizing experience enables:

Problems are ill-defined more often than not. Objectives and goals are vague, changing, and often in conflict with one another. In most cases the design process is one of collective inquiry and search where several actors, in cooperation or conflict, define relevant problems and possible solutions - doing so more or less simultaneously. Problems and ends can not be taken as givens, they are negotiated and clarified during the design process. [p. 173]

A field study of information systems development examined how project participants communicated their knowledge, assumptions, and expectations to negotiate a shared understanding of information systems (IS) requirements (Davidson 1996). Creating and maintaining accounts of actions and events in the IS development projects were critical sensemaking processes that shaped participants' interpretation of IT requirements and influenced their decisions about the design and implementation of IT artifacts. This interpretive process of narrativizing experience was evident both in informants' retrospective accounts of project events during research interviews and in project members' interactions during day-to-day project activities as they reacted to and accounted for events that affected the development project.

These findings are described in detail elsewhere (Davidson 1996). The goal here is to describe an analytic approach for examining such narratives, to illustrate its application in the analysis of project history narratives collected during the field study, and to consider how narrative analysis may inform our understanding of the social cognitive worlds of participants in IS development activities. In this endeavor, we rely primarily on Mishler's (1986a, 1986b) work on narrative analysis of interview data, which is reviewed in the next section.

\section{ANALYZING NARRATIVES IN INTERVIEW DATA: AN OVERVIEW}

In Research Interviewing: Context and Narrative, Mishler (1986b) reviews and critiques various methodological approaches for analyzing narratives produced in the context of research interviews. He first considers methods that focus on the analysis of structural components of narratives. Citing the work of Labov and Waletzky (1967) and Labov (1972), Mishler notes that the focus of their analytical method is identification of narrative clauses or "complicating actions" within the text of a story. Narrative clauses are those clauses which depend on a strict sequential ordering for

${ }^{1}$ See Boland and Schultze (1995) for one example. 
their meaning. For example, in the sequence of clauses "The dog bit Mary, and Mary cried," the meaning of the clause "Mary cried" is implied by its temporal ordering after the clause "The dog bit Mary." Nonnarrative clauses, which may also occur in a narrative account, include a narrator's abstract or summary of the story's point, orientation or contextual information, evaluative comments, the result or resolution of actions, and a coda or return to the conversation from the story. Mishler comments that this method of categorizing portions of a narrative text into structural categories is similar to content analysis methods used in qualitative data analysis and therefore should be accessible to researchers familiar with these methods.

In his critique of the Labov-Waletzky's model, Mishler notes that, although temporal ordering is given theoretical importance, the model focuses on further categorization and analysis of the evaluative components of a story. He reviews Labov's (1982) solution to this apparent paradox, in which a higher level of abstractions is achieved by characterizing the narrative clauses in terms of the social meanings of the events to which they relate. Using Goffman's concept of a Move, the skeletal outline of narrative clauses is transformed into a highly abstract sequence of Moves to reveal patterns of social positioning in interaction.

Drawing next on the work of Agar and Hobbs (1982), Mishler considers how the structure of content in a narrative may reveal implicit meaning. In this approach, the narrator's intentions and narrative strategies to produce a coherent account are examined in terms of coherence relations among utterances or narrative segments. In the Agar-Hobbs model, there are three general types of coherence which impart a form of unity to a narrative text: (a) global coherence, which relates to the speaker's overall plan or intent for the narrative; (b) local coherence, which refers to the function of an utterance within the immediate text segment; and (c) themal coherence, which suggests the narrator's assumptions, beliefs, and goals that reoccur throughout the narrative. Examining how coherence is manifest in a narrative reveals aspects of the structure and content of the narrator's cognitive world. Mishler concludes that the researcher cannot avoid applying his own cultural understanding in this interpretive process and, in this way, enlarging the text with his or her own knowledge, values, and beliefs. His conclusion is similar to the position taken by Polanyi (1989) in her analysis of cultural values and beliefs in conversational stories.

Mishler contends that the influence of the interaction context in a research interview on informants' production of narrative accounts has been largely ignored or has not been systematically addressed in these types of research approaches. Instead, the researcher is "written out" of the context with the assumption that he or she has had no significant influence on the production of the narrative. Drawing on the work of Paget $(1982,1983)$ and Bell (1983) on life history interviews, Mishler suggests that narratives are a joint production of interviewer and interviewee which reflects ongoing shifts in the reciprocal dual roles of interviewer/interviewee and listener/narrator. He concludes that systematic analysis of the interview context contributes to a more adequate interpretation of the narrative's meaning. 
How a narrative is identified and how it is bounded in the text of an interview influences interpretation of the narrative. In the Labov-Waletzky model, narrative and nonnarrative portions of an interview are separated and attention is focused on the narrative statements. In the Agar-Hobbs model, all portions of the text potentially contribute to the coherence and the interview (or major portions of it) are treated as one narrative. In Bell's approach to life history narratives, stories are bounded within the interview and linkages between stories or episodes are examined.

Despite these methodological differences, Mishler (1986a, 1986b) suggests that a richer interpretation of a narrative is made possible by considering the insights available from all of the three approaches (structural, meaning, and interaction analysis). In the analysis of a text segment from a research interview, he first uses the Labov-Waletzky model to classify portions of the narrative as orientation, the narrator's abstract, complicating actions or narrative clauses, and resolution or outcome (Mishler 1986a). By making inferences informed by the model, he identifies the core narrative as the narrator's "point" in the story. He then applies Labov's method (1982) to summarize the narrative clauses into a highly abstract plot sequence of Moves (an offer-refusal-counteroffer sequence) through which threats to social status are reduced. Using the notions of global and themal coherence from the Agar-Hobbs model, Mishler then considers how various segments of the text relate to the narrative as a whole and, through this analysis, he interprets the narrative as the informant's attempt to present himself according to a cultural ideal (being a self-reliant and responsible person). Mishler notes that both the production of the narrative and his interpretation of it depended on the shared recognition of cultural values between interviewer and interviewee. Finally, Mishler assesses the interaction context of the research interview, which he characterizes as bordering on an adversarial struggle for control of the interview. The interviewee evaded direct answer to some questions, digressed with many stories and concealed relevant information that would be unflattering to him.

In his sequential application of the three analytic approaches, Mishler (1986a, 1986b) does not attempt to integrate the methods. Nor does he claim to have arrived at one, true interpretation of the narrative account. Instead, he demonstrates that narratives are multifaceted, and that using a variety of analytic lenses provides deeper insight into their multiple meanings as well as into the assumptions and values which inform meaning making through narrative construction. The narrative analytical approach used here to examine project history narratives is modeled on Mishler's three-steps of structural, meaning, and interaction analysis. The next section describes the current application of these methods in detail. 


\section{ANALYZING PROJECT HISTORY NARRATIVES: A METHODOLOGICAL APPROACH}

The narratives examined in this paper are drawn from interview data collected as part of a year-long field study of requirements definition activities during information systems development (Davidson 1996). The research was conducted at Group Health, Inc. (GHI), a nonprofit health care insurance company in the eastern United States. For several years before the research project began and throughout the study period, GHI experienced major changes in its market. Executives at the company responded with new strategies, organizational restructuring, new product introductions, and IS development initiatives aimed at improving management information. A year before the study began, GHI executives outsourced the entire IS operations and development functions to an IT vendor, Information Systems, Inc. (ISI). Not surprisingly, this organizational context posed significant challenges to project teams that were developing and implementing large-scale information systems.

One of the projects examined at GHI was the INFOSYS project. The project involved building a relational database of historical data from transaction processing systems and implementing a purchased software package, the INFOSYS system, which contained analytical algorithms and had a client-server based, graphical user interface (GUI). During its three year history, the project had gone through a number of episodes in which project activities were halted or the project was redirected. Data on the INFOSYS project was collected over a four month period from project files and documents and through retrospective interviews with thirty informants at who had some involvement in the project, either as team members, sponsors, developers, or potential users. In interviews, a semi-structured interview protocol was used to ask informants to reflect on their understanding of the project and the IT application, their own and others' actions, and events in the organization that they believed had affected the project. Interviews were audio taped and transcribed.

In many instances, the informant's response to questions took the form of an extended narrative history of the project, in which they told stories about major events and episodes in the project, identified key actors, attributed goals and motives to these actors, and so on. Methodological decisions must be made about how to identify and bound such narratives (Mishler 1986b). No attempt to treat the entire interview as one narrative was made. Instead, the interview text was considered a series of narratives, some of them with multiple episodes, interspersed with nonnarrative interchanges and information. Interest then was in those sections of the interview in which the informant narrated portions of the INFOSYS project history, although both narrative and nonnarrative clauses within these sections were examined.

To illustrate this approach to narrative analysis, in this paper we examine the narrative accounts of the origins of the INFOSYS project from three key informants: the project manager, the project sponsor, and a GHI executive. In interviews, these informants were asked to describe, from their perspective, how and why the INFO- 
SYS project got started. Each individual had a unique perspective on the project's origins which reflected not only their experiences with project activities but also their knowledge, assumptions, and expectations about the project's purpose and definition, technology development strategies, desirable features of the IT application, problems or opportunities at GHI to be addressed through the technology, and so on. The full text of the narrative accounts, extracted from the interview transcript, are documented in Appendices A, B, and $C$ respectively.

Following Mishler's (1986a, 1986b) example of a three-phased examination of structure, meaning, and interaction context, the first step was the structural analysis of the project history narrative. To identify structural components, each informant's narrative account was divided into segments of partial sentences, complete sentences, or strings of sentences which contained distinctive information. To classify segments, the four structural components used by Mishler (1986a) - orientation, the narrator's abstract, complicating actions or narrative clauses, and resolution or outcome - were considered as well as the narrator's perspective, actors identified in the narrative, the problematic situation articulated by the narrator, and the goal/problem solution perceived by the narrator (see Table 1). These categories better fit the data in the problem-solving narratives analyzed. They also reflect Bruner's (1990) four "crucial grammatical constituents" of narrative cognitive processes: 1) goal-directed action by humans; 2) a sequential order to events and states moving through time; 3 ) a sense of the canonical and the exceptional or noncanonical; and 4) a narratorial voice or perspective.

The results of this first step of the structural analysis are summarized in Exhibits 1,2 , and 3. A next step was to develop an abstract of the actions and events which constituted the story line. Unlike Mishler (1986a), Goffman's Move concept was not used to create the plot abstract, because the concept of a Move, which relates to the structure of interpersonal interactions, was not the focus of this research. Instead, the narrative accounts examined were stories of the problem-solving activities of individuals and groups in an organizational setting. To develop the abstract of the underlying plot sequence, generic descriptions of the actions or events described were used. For example, action clauses such as "a few of us went around and looked at different alternative ways of doing this" or "we explored doing it on our own or going with and outside vendor" were characterized generically as "a search for alternative solutions."

In the next analytic step, the Agar-Hobbs model for coherence relations was used to examine how various narrative segments conveyed unity to the narrative account of the project's origins. In this step, segments which did not directly contribute to the plot sequence or were parenthetical in the movement of the plot, such as orientation and contextual information, were particularly revealing. Segments that had global and themal coherence provided insights into how the informants made sense of the events and actions depicted in their accounts, the meaning they attributed to them, and key assumptions and expectations they drew on to attribute meaning to actions and events. Comparisons among the three narrative accounts highlighted individuals' assumptions as well as shared assumptions. 
Table 1 Classification Categories for Narrative Segments.

\begin{tabular}{|l|l|}
\hline Category & Description \\
\hline Narrator's abstract & $\begin{array}{l}\text { Segments in which the narrator summarizes the events and } \\
\text { outcome of the story. An abstract is not always present. }\end{array}$ \\
\hline Narrator's perspective & $\begin{array}{l}\text { Segments or use of language (e.g., "T" or "we" versus } \\
\text { "they") in which the narrator reveals his or her perspective } \\
\text { on events in the narrative. }\end{array}$ \\
\hline $\begin{array}{l}\text { Orientation/contextual } \\
\text { descriptions }\end{array}$ & $\begin{array}{l}\text { Segments in which the narrator provides contextual infor- } \\
\text { mation which does not contribute to the movement of ac- } \\
\text { tion through time. These are not always present. }\end{array}$ \\
\hline Actors & $\begin{array}{l}\text { Segments or use of language (e.g., "I" or "we" versus } \\
\text { "they") which indicate who carried out actions or contrib- } \\
\text { uted to events depicted in the narrative. }\end{array}$ \\
\hline Problematic situation & $\begin{array}{l}\text { Segments in which the narrator describes his or her percep- } \\
\text { tions of the noncanonical or exceptional circumstances } \\
\text { which motivates actions described in the narrative. }\end{array}$ \\
\hline Goal/problem solution & $\begin{array}{l}\text { Segments in which the narrator describes his or her percep- } \\
\text { tions of how the problematic situation could be or was re- } \\
\text { solved. }\end{array}$ \\
\hline Actions and events & $\begin{array}{l}\text { Narrative clause segments: } \\
\text { - Actions are activities that occur during the time span of } \\
\text { the narrative that have a strict temporal sequencing. } \\
\text { Past actions or flashbacks serve as orientation clauses. } \\
\text { Events are recognized changes in state, such as comple- } \\
\text { tion of an activity or arriving at a decision point. }\end{array}$ \\
\hline $\begin{array}{l}\text { Segments in which the narrator describes the perceived out- } \\
\text { come of actions and events, such as resolution of the prob- } \\
\text { lematic situation by achieving the goal. }\end{array}$ \\
\hline
\end{tabular}

The last step in the narrative analysis was to assess how the interaction context may have affected the informant's production of the narrative account. The goal in each interview was to elicit open-ended responses to questions and the informant was generally encouraged to answer as he or she was inclined. However, by using a semistructured interview protocol, the informant's narratives were guided to topics of interest in the study. Thus, the informant's narrative was a response to the questions asked and to how their response was guided. The relationship of the researcher with 
the informant at the time of the interview and how this may have influenced his or her decision about what information to relate was then considered.

In the next section, the application of the three step analytical approach to three narrative accounts of the origins of the INFOSYS project is illustrated. For brevity in presentation, the analysis of the project manager's account is discussed in detail and then the analysis of her account is compared and contrasted with the analyses of the project sponsor's and executive's accounts.

\section{HOW DID THE INFOSYS PROJECT GET STARTED? THE PROJECT MANAGER'S NARRATIVE}

In response to a request that she describe how the INFOSYS project got started, the project manager described her experiences with and perceptions of the events and activities that led to the formulation of the project (see Appendix A). Following the methodology described above, the structural components of the narrative were analyzed first. The results of this analysis are documented in Exhibit 1.

The structural analysis focused on the identification of the narrative clauses and creation of an abstract of the plot sequence through which the narrator organized her explanation for her own and others' actions. The sequence of events in the problemsolving plot abstract revealed through this analysis were i) identification of a problem or need, ii) evaluation of alternative solutions, and iii) selection of an alternative. In the first problem-solving sequence, "there was a need identified to be able to provide accounts with some access to their own data" (lines 45-6), alternative solutions were considered (lines 47-51, 55-6, 57), and the best solution (INFOSYS) was chosen (lines 58-60, 61-64). The problem-solving plot was complicated, however, by the unexplained failure of management "a couple levels up" to support the project in this first project episode (lines 65, 66-67), resulting in a temporary ending to the story (line 68). The story continued in the next episode with a second problem-solving sequence in which a major customer's request for the INFOSYS software created a new need (lines 75-79; 80-82; 84-86), alternative solutions were again evaluated (lines 91-92), and INFOSYS was finally selected as the best alternative (lines 93100). The outcome of this episode was GHI's commitment of resources to acquire and implement the software (lines 101-106).

In the analysis of meaning, the local, global, and themal coherence of segments in the narrative were considered. Take, for example, the informant's entree into her story of the INFOSYS project's origins: "Really, there have been several fits and starts" (line 15). This utterance was locally coherent, functioning as a transition from the interviewer's question (lines 10-13) into the informant's story. It was globally coherent, serving as the abstract for the informant's story and setting the stage for the informant's lengthy account of project episodes that followed. Additionally, this ut- 
Exhibit 1 Structural Analysis of Project Manager's Narrative.

\begin{tabular}{|c|c|}
\hline $\begin{array}{l}\text { Narrator's } \\
\text { Abstract: }\end{array}$ & "Really, there have been several fits and starts..." (line 15) \\
\hline $\begin{array}{l}\text { Narrator's } \\
\text { perspective }\end{array}$ & $\begin{array}{l}\text { "I was in the account reporting department" (line 17) } \\
\text { "There was a...systems team that I managed..." (lines 20-21) } \\
\text { "So I didn't hear anything else about it for a while." (line 69) } \\
\text { "...so I wasn't involved in the actual going around and interviewing vendors at } \\
\text { this point..." (lines 88-89) } \\
\text { "And I was a part of that uh...effort..." (line 107) }\end{array}$ \\
\hline $\begin{array}{l}\text { Orientation/ } \\
\text { contextual } \\
\text { descriptions: }\end{array}$ & $\begin{array}{l}\text { In lines 21-27 the informant uses a scenario to describe the account reporting } \\
\text { process. } \\
\text { In lines } 52-54 \text { the informant mentions a related IS initiative. } \\
\text { In lines } 70-74 \text { the informant describes the organizational change affecting her } \\
\text { area. } \\
\text { In line } 83 \text { the informant refers to the outsourcing of the IS department. }\end{array}$ \\
\hline Actors: & $\begin{array}{l}\text { "I" (project manager); "we" (unspecified group); “a few of us" (line 47); } \\
\text { "a couple of levels [managers]" (line 65); } \\
\text { RBC (lines 75, 80, 94, 98); marketing reps (line 80) } \\
\text { "a team...at a higher level" (line 87); "Dave...people at his level" (line 90) }\end{array}$ \\
\hline $\begin{array}{l}\text { Problematic } \\
\text { solution: }\end{array}$ & $\begin{array}{l}\text { In lines } 28-44 \text {, the informant uses a narrative scenario to describe the ineffi- } \\
\text { ciencies of the account reporting process. ("But the problem that we saw...") }\end{array}$ \\
\hline $\begin{array}{l}\text { Goal/problem } \\
\text { solution: }\end{array}$ & $\begin{array}{l}\text { "and we were looking at providing accounts with some access that they could } \\
\text { have to their own data" (lines 18-19) }\end{array}$ \\
\hline $\begin{array}{l}\text { Actions and } \\
\text { events }\end{array}$ & 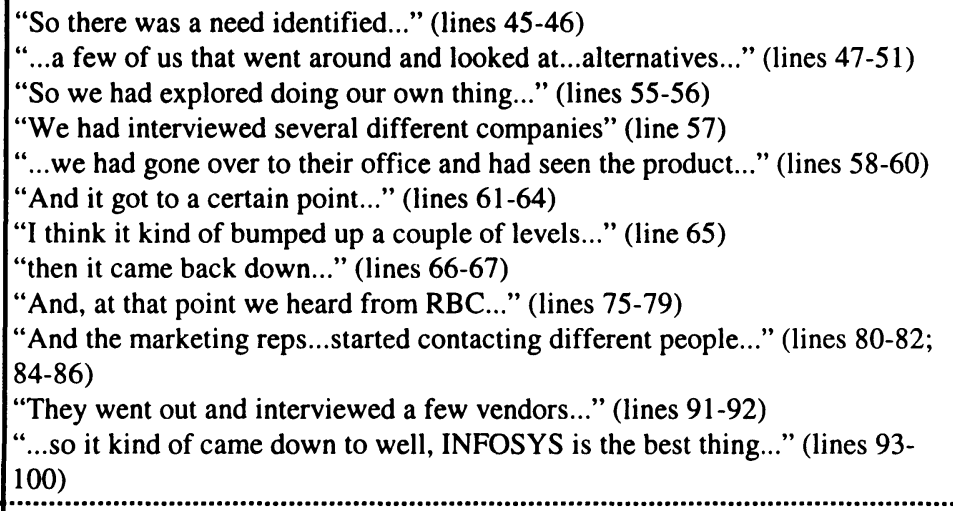 \\
\hline Outcome: & $\begin{array}{l}\text { "We kind of went "bye." (In line } 68, \text { the informant describes an intermediate } \\
\text { outcome.) } \\
\text { "So at that point, a team was put together...to look at this and negotiate a con- } \\
\text { tract..." (In lines } 101-106, \text { the informant describes the final outcome of these } \\
\text { episodes. }\end{array}$ \\
\hline
\end{tabular}


terance had themal coherence with the informant's depiction of her own and other's long struggle to overcome problems and disruptions that delayed, halted, or altered the course of project activities. Thus, she implied that there was no simple answer to the question of how and why the INFOSYS project got started but that the answer lay in its "fits and starts."

In a similar manner, other segments of the narrative were analyzed. Some segments were only locally coherent. For example, the informant's statement in line 17 ("I was in the account reporting department") served primarily to clarify the narrator's perspective in the actions described in lines 18-19 ("and we were looking at providing accounts with some access"). Such segments were of less interest in the analysis of meaning than segments that were globally or themally coherent. Two merit special attention here.

In the narrative segment in lines $28-44$, the project manager stated her perception of the problematic situation, clearly introduced with the verbal cue "but the problem that we saw," and using the pronoun "we" to imply that her perception of the problem had been shared with others. The informant's dramatization of the problem through a narrative scenario of the inefficient and frustrating reporting process suggested that this segment was of particular importance to the narrator's purpose in the narrative. It had global coherence, because it provided the motivation the actions and events that led to acquisition of the INFOSYS system. It also had themal coherence, expressing themes that reoccurred throughout the project manager's narrative of the INFOSYS project about the desirability of having end-users access data directly and the advantages of freeing programmers from producing the reports. Her articulation of the reporting problem also related to her interpretation of the INFOSYS technology, with its GUI interface, as the technology which would allow GHI to "provide accounts with some access to their own data" (lines 45-46).

Related to her articulation of the problematic situation in this segment is the project manager's dismissal of one of alternative solutions in lines 52-54 ("You know, we had been building our own repository. But didn't, you know, have the friendly front-end type thing"). At first glance the informant appeared simply to provide contextual information that related to her preceding statement, that alternative solutions to the reporting problem were being explored including the "build or buy option" (lines 4851), and the following statement, that the team had decided on "going with an outside vendor" (lines 55-56). However, consideration of the global and themal coherence of this segment with other parts of the narrative suggested other meanings implicit in this statement. The segment was globally coherent with the underlying plot sequence of problem identification, evaluation of alternatives, and selection of the best alternative, suggesting that this alternative (using the in-house developed system) had been given due consideration but dropped because it lacked "the friendly front-end type of thing." Themal coherence with the project manager's depiction of the INFOSYS software package as the only viable solution (lines 93-100) was also evident, particularly later in the interview when she emphasized the importance of the graphical user interface (GUI) feature of the INFOSYS software. 
In the last analytic step, the influence of the interaction context on the project manager's production of the narrative account of the origins of the INFOSYS project was assessed. The context was a formal research interview conducted with the project manager. Formal aspects of the setting were evident in note taking and recording of the interview and in guiding of the discussion with questions. By telling her story, the project manager fulfilled her agreement to provide information about project events for the research project. Her narrative account reflected the request (lines 1-6) that she describe the project from her own perspective and relate project events to other happenings in the company. In doing so, she meticulously specified which events she had participated in and which she had only second hand knowledge of (see narrator's perspective in Exhibit 1). However, a degree of rapport with the project manager had been established earlier after several informal meetings with her to discuss including the INFOSYS project in the research project at GHI and in informal discussions about similarities in professional background and personal circumstances. As she told her story, she appeared to take advantage of the opportunity to relate her experiences with this frustrating project to an informed and sympathetic listener. After clarifying what information was being requesting (line 8), she largely ignored the suggestion that she skip the details to describe how and why the project got started (lines 10-13) and instead proceeded with a 1600 word, detailed narration of project events. By shifting from the role of interviewer to listener and not interrupting, the researcher cooperated with her assumption of the authority to tell the story of the project in her own way, that is, through the story of its "fits and starts."

Through these analytic steps, a fuller interpretation of the possible meanings of the informant's narrative of the origins of the INFOSYS project was achieved. Her problem solving plot implied the rational and objective nature of the actions which lead to purchase the INFOSYS package. Her story became not that of yet another over-budget, over-schedule IS development project but one of a lengthy and difficult struggle by herself and others to solve a long-standing problem at GHI and to satisfy important customers. The epic-like proportions of her story were even more strongly evident in her later accounts of incidents in which the villain-like outsource organization temporarily "killed" the project or attempted to "sabotage" it. Given these insights into her story, questions arise about the assumptions, values, or beliefs that informed the project manager's narrativizing of actions and events in the INFOSYS project. What do they tell us about her social cognitive world? To what extent was her interpretation shared by others? Comparing the results of the analysis of the project manager's narrative to the analyses of the project sponsor's and executive's accounts highlighted similarities and differences in the narrative structure, in the structure of content and the implications for meaning of the narratives, and the influence of the interaction context. In this way, individual assumptions, values, and beliefs which informed their meaning making became clearer, as did the extent to which these assumptions were shared with others at GHI. 


\section{HOW DID THE INFOSYS PROJECT GET STARTED? A COMPARISON OF ACCOUNTS}

The summary of the structural analysis of the INFOSYS project sponsor's and the executive's narrative are provided in Exhibits 2 and 3, and the full text of the interview segments are contained in Appendices $B$ and $C$ respectively. Not surprisingly, there were differences evident in the three accounts. Each informant constructed an account of the origins of the INFOSYS project using his or her own experience with and knowledge of project events. The project manager's narrative reflected her involvement in the day-to-day operation of the project. The perspective of the project sponsor was consistent with his responsibility for a variety of MIS support activities in the accounting and actuarial departments. The executive's perspective was that of a senior manager concerned with the company's standing with competitors and customers.

Beyond these expected differences, comparison of the structural analysis of the three accounts indicated other interesting variations in the narratives. Interestingly, each of the three informants articulated the problematic situation which motivated the actions and events in their narrative differently. The project manager's narrative focused on the inefficient utilization reporting process as the problematic situation and its resolution by giving accounts direct access to data. In her story, INFOSYS emerged as the best choice among alternative solutions. The project sponsor's narrative suggested that the project grew out of a long-acknowledged desire at GHI to have a data warehouse or MIS system. Providing the INFOSYS software package in response to the RBC, Inc.'s request was then "a fast way to jump start" into having an MIS (lines 47-49 in Exhibit 2). In his narrative, the executive stressed recognition of an opportunity to gain competitive advantage by excelling in analytical utilization reporting for customers (lines 37-39, Exhibit 3), and he perceived the answer to be the technology provided by INFOSYS, Inc.

Although these diverse interpretations of the problematic situation intersected in the rationale for GHI's decision to acquire the INFOSYS package, each informant identified different actions and events that led to this decision. The plot sequence in the project manager's narrative was a problem identification/alternative evaluation/selection sequence of events. The project sponsor's narrative was generally consistent with the project manager's account, but it differed in the details of actions and events noted. He briefly mentioned the first episode in which GHI personnel evaluated the INFOSYS package (lines 13-15, Exhibit 2) and then, noting RBC's action (line 16), he dramatized RBC, Inc.'s request that GHI purchase INFOSYS with a paraphrase (lines 17-21) and gave his own explanation of the logic of RBC's request (lines 22-36) which provided the impetus for the project. In the plot sequence in this narrative, there was no evaluation of alternatives. Instead, a change trigger was acknowledged (lines 16), information was gathered (line 37), and an opportunity was recognized (lines 38-42) to satisfy a long-standing goal of having an MIS. 
Exhibit 2 Structural Analysis of Project Sponsor's Narrative.

\begin{tabular}{|c|c|}
\hline $\begin{array}{l}\text { Narrator's } \\
\text { Abstract: }\end{array}$ & $\begin{array}{l}\text { “...so we saw it as, although an expensive way, a fast way to jump start us into } \\
\text { a management information situation." (lines } 47-49 \text { ) }\end{array}$ \\
\hline $\begin{array}{l}\text { Narrator's } \\
\text { perspective: }\end{array}$ & $\begin{array}{l}\text { Narrator's participation in the events is implied through his first-person plural } \\
\text { narration of events (lines } 7,10,37,38,47 \text { ). }\end{array}$ \\
\hline $\begin{array}{l}\text { Orientation/ } \\
\text { contextual } \\
\text { descriptions: }\end{array}$ & In lines $11-12$, the informant describes the IS organization. \\
\hline Actors: & $\begin{array}{l}\text { "We" (unspecified) and "I" (lines 7, 10, 37, 47) } \\
\text { RBC, Inc. (line 16) } \\
\text { "I and the IS people I was working with" (line 38) }\end{array}$ \\
\hline $\begin{array}{l}\text { Problematic } \\
\text { situation: }\end{array}$ & $\begin{array}{l}\text { "We were, we had been talking for years about a data warehouse, an MIS sys- } \\
\text { tem..." (lines 7-9) }\end{array}$ \\
\hline $\begin{array}{l}\text { Goal/problem } \\
\text { solution: }\end{array}$ & $\begin{array}{l}\text { In lines } 37-42 \text {, the informant cites INFOSYS as the solution to the need for an } \\
\text { MIS. } \\
\text { In lines } 22-36 \text {, he outlines the logic of GHI's decision to provide the system } \\
\text { for its customer, RBC. } \\
\text { In lines } 39-42 \text {, he links this approach to the goal of having an MIS. } \\
\text { In lines } 43-47 \text {, he qualifies to what extent INFOSYS is a solution to the MIS } \\
\text { issue. }\end{array}$ \\
\hline $\begin{array}{l}\text { Actions and } \\
\text { events }\end{array}$ & $\begin{array}{l}\text { “...we were talking about it (an MIS) about two and a half years ago" (line 10) } \\
\text { “....and INFOSYS was one of the, was something that was looked at but not } \\
\text { looked at seriously" (lines } 13-15 \text { ) } \\
\text { “....and then RBC came along...” (line 16; lines } 17-21 \text { describe RBC's request) } \\
\text { ".So, we looked at INFOSYS..." (line } 37 \text { ) } \\
\text { “.... [we] saw it as a solution to...the RBC issues...and a quick way to jump us } \\
\text { into having a management information system" (lines } 38-42 \text { ) }\end{array}$ \\
\hline Outcome: & $\begin{array}{l}\text { “...so we saw it as, although an expensive way, a fast way to jump start us into } \\
\text { a management information situation" (lines } 47-49 \text { ) }\end{array}$ \\
\hline
\end{tabular}

Similarly, the executive's narrative was not inconsistent with the Project Manager's, but it provided details of actions and events that reflected his interpretation of the problematic situation as an opportunity to gain competitive advantage with customers. He began his narrative by setting the stage with a description of a marketing consultant's report on customer's interest in utilization reporting, an event not mentioned by either the project manager or project sponsor. His implication that in-house capabilities had been considered but dismissed (lines 49-52) was consistent with the project manager's account. However, the plot sequence evident in his narrative was one of environmental scanning (lines 8-9), organizational assessment (lines 44-48), reaction to environmental triggers (lines $77-81 ; 82-84 ; 92-93$ ), information gathering (line 85,91 ) and competitive action (line 99). In this narrative sequence, he inserted 
Exhibit 3 Structural Analysis of Executive's Narrative.

\begin{tabular}{|c|c|}
\hline $\begin{array}{l}\text { Narrator's } \\
\text { Abstract: }\end{array}$ & “Obviously, an opportunity for somebody to do it well" (lines 40-41) \\
\hline $\begin{array}{l}\text { Narrator's } \\
\text { perspective: }\end{array}$ & $\begin{array}{l}\text { "When I first came here back in '91" (lines 7-8) } \\
\text { "So, I was part of a group of folks here" (lines 42-43) } \\
\text { "XYZ expressed the interest before I got here" (lines 69-70) }\end{array}$ \\
\hline $\begin{array}{l}\text { Orientation/ } \\
\text { contextual } \\
\text { descriptions: }\end{array}$ & $\begin{array}{l}\text { In lines 8-17, the informant describes a market survey of GHI's customers. } \\
\text { In lines 66-68, the informant describes customer's interest in INFOSYS. } \\
\text { In lines 69-76, the informant describes an earlier event in which customer } \\
\text { XYZ acquired INFOSYS. } \\
\text { In lines 86-90, the informant cites the CEO's support for INFOSYS. }\end{array}$ \\
\hline Actors: & "l" and "we" (unspecified); "two or three of us" (line 43) \\
\hline $\begin{array}{l}\text { Problematic } \\
\text { situation: }\end{array}$ & $\begin{array}{l}\text { "...nobody in the marketplace did it well. Nobody..." (In lines } 18-29 \text {, the } \\
\text { informant describes customers' interest in account reporting. In lines } 30-35 \text {, } \\
\text { he clarifies which accounts are affected, and in lines } 37-39 \text {, he states that no } \\
\text { providers are satisfying customers.) }\end{array}$ \\
\hline $\begin{array}{l}\text { Goal/problem } \\
\text { solution: }\end{array}$ & $\begin{array}{l}\text { "INFOSYS, on the other hand, has a tool..." (lines } 53-65 \text { describe why the } \\
\text { software company has a solution to the perceived opportunity) }\end{array}$ \\
\hline $\begin{array}{l}\text { Actions and } \\
\text { events: }\end{array}$ & $\begin{array}{l}\text { “...we had just completed some work with the Dryer poll people" (lines 8-9) } \\
\text { "We kind of did a quick look" (line } 44 \text {; lines } 45-48 \text { clarify what was exam- } \\
\text { ined) } \\
\text { "We didn't have anything" (line } 49 \text {; lines } 50-52 \text { clarify what actually } \\
\text { existed) } \\
\text { "and RBC went out and looked at it" (lines 77-81) } \\
\text { "and they asked us if we would be interested in acquiring it..." (lines 82-84) } \\
\text { "So we took a look at it [INFOSYS]" (line 85) } \\
\text { "We all looked at it [INFOSYS]" (line 91) } \\
\text { "and they also had just announced the product for the desktop..." (lines 92- } \\
93 \text {, with clarification in lines } 94-98 \text { ) } \\
\text { "and so we went out and acquired the license..." (line 99) }\end{array}$ \\
\hline Outcome: & $\begin{array}{l}\text { "and it turned out we were either the second or third largest company in the } \\
\text { country...to pull the data down to the PCs for our accounts" (lines 100-104) }\end{array}$ \\
\hline
\end{tabular}

a rationale for using the INFOSYS package (lines 53-65 in Exhibit 32) and flashbacks to earlier actions by RBC, Inc. (lines 67-68) and another customer (lines 66, 69-76) which supplemented his interpretation of the competitive opportunity (lines 18-29).

Earlier, the local, global, and themal coherence of the project manager's narrative abstract to consider the meanings implicit in her narrative were examined. Differences in the narrative abstracts of the project sponsor and executive suggested that the three informants attributed different meanings to the events that led to the formulation 
of this project. The project sponsor's narrative abstract in lines 47-49 ("So we saw it as... a fast way to jump start us into a management information situation") was locally coherent with his preceding remarks about the INFOSYS package (lines 3846) and globally coherent with his intent to tell the story of the project's origins that contradicted the assumption that the request by $\mathrm{RBC}$, Inc. was the impetus for the project. By subsuming the influence of $\mathrm{RBC}$, Inc. in the decision to acquire INFOSYS to the long-standing goal of having an MIS system (lines 7-10), his narrative summary integrated his explanation of events. Themal coherence was evident throughout the interview in his assertions that there had been an understanding that INFOSYS would serve as the basis for an MIS system at GHI, Inc.

The executive's narrative abstract in lines 40-41 of Exhibit 3 ("Obviously, an opportunity for somebody to do it well") suggested yet a third interpretation of the events that lead to the formulation of the project. This statement was locally coherent with the preceding opportunity description and globally coherent as a transition from the recounting of background events that set the stage for the problem definition to the description of activities that led to the selection of INFOSYS. The statement also had themal coherence with the executive's conclusion about the outcome of the story, that GHI became one of the first large companies to "pull the data down to the PC's for our accounts" (lines 100-104).

Although it is not possible to completely understand the dynamics at work in the context of a research interview, assessing the degree to which the interaction settings may have influenced production of the narrative accounts is useful when considering the import of these differences. Earlier the interaction context in the project manager interview was described. It is important to note that the project sponsor's narrative was a response to a more pointed question about whether the INFOSYS project had originated in RBC's request. His narrative can be seen as a refutation of this assumption. Because the rapport was not as strong as with the project manager and because the research project had been authorized by one of his opponents in the controversies surrounding the INFOSYS project, his construction of the narrative account may also have been motivated by his desire to depict the INFOSYS project as a broad-based IS solution. The interaction context in the interview with the executive was yet again different. Initially, the executive sponsored the research project at GHI, and the researcher had met with him on three other occasions and had conducted an earlier interview. As a senior executive at GHI, he apparently had nothing to lose or gain through his interview with me, and the tone of the interview was one of helpfulness and information sharing.

Having considered the possible influence of the interaction context on production of these informants' narrative accounts of the origins of the INFOSYS project, substantive differences revealed through the narrative analysis remain. The three informants did have different perspectives on the project, but they were working with roughly the same "facts." This was evident in similarities in their accounts, such as the first, informal evaluation of the INFOSYS package and the influence of RBC, Inc. However, each narrator constructed a different story to account for actions and events 
that lead to the formulation of the INFOSYS project. The three informants used different problem-solving plot sequences to organize the actions and events, which implied different causal relations among actions and events. They offered different explanations of the problematic situation that motivated the INFOSYS project and attributed different meaning to the events in the project. Differences in their ways of narrativizing an account of the project's origins may have reflected their ongoing need to make sense of and account for the issues each faced related to the project. After the long delayed pilot for RBC, Inc. was implemented, various user groups began placing demands for implementation of software features and data sources, and the project manager was still struggling to set and maintain a direction for implementation of the INFOSYS software and database. The project sponsor, on the other hand, had fought budget battles with the outsourcing company, ISI, Inc., to fund development beyond the RBC pilot installation and, at the time of the research interview, he was contesting the claim of a subsidiary's IS group to have a superior MIS/warehouse product. Although the executive depicted INFOSYS as a strategic technology and concluded his narrative with the assertion that GHI was one of the first large companies "to pull data down to the PC's for our accounts," this aspect of the technology had never been implemented and, in fact, the INFOSYS system was not being used even by RBC, Inc. However, the executive had recently assumed responsibility for technology initiatives with customers and providers, and his story of this earlier incident, though inaccurate in fact, supported his call to extend use of the PC feature to a variety of customers.

Through the systematic narrative analysis of each informant's story and comparison of the analysis of multiple stories, such differences in sensemaking and interpretation become evident. In the next section, the insights that narrative analysis may provide into the social cognitive worlds of participants in IS development are considered more generally and we discuss how narrative analysis may inform IS research.

\section{DISCUSSION}

The structural analysis of informants' stories described in this paper provides a systematic way to summarize key aspects of lengthy narrative accounts that often occur in research interviews. By identifying and isolating narrative clauses, generic plot sequences that underlie the sequence of actions and events identified by the narrator and that guide his or her interpretation and presentation of events are revealed. Plot sequences used by multiple informants may then suggest prototypical rationales which IS participants apply when they account for and interpret the meaning of organizational activities through which information technologies are developed, implemented, and used. In the three narratives of the origins of the INFOSYS project considered here, narrators' variations on the problem-solving plot suggest several interesting questions. Why did the project manager's narrative include the evaluation of alternatives in the problem-solving plot, whereas the project sponsor's and execu- 
tive's narratives did not? Does their selection of different plots indicate differences in perspective, in organizational role, in power and authority? Would they use different plot sequences to organize their recounting of events in different circumstances?

Consideration of the local, global, and themal coherence of segments of a narrative guide the analyst's assessment of the possible meanings of the narrative. Identification of statements with themal coherence may indicate aspects of the organizational context that influenced the narrator's interpretation. For example, interjections by both the project manager ("there's no ISI at this point," line 83) and the project sponsor ("MIS, before they were outsourced," line 12) in their recounting of events referred to the outsourcing of the IS organization at GHI. Their parenthetical interjection of this contextual information indicated not only the importance this organizational change had for their understanding of the INFOSYS project but also signaled its influence on IS participants' interpretation of systems development activities at GHI. Recognition of the coherence function of such statements within a narrative depend in part on their familiarity with the organizational context. In this case, knowledge of the controversies surrounding the IS outsourcing facilitated perception of the global and themal coherence of statements about outsourcing in INFOSYS project history narratives.

In some ways the narrative analysis approach presented here, particularly the classification of narrative segments as structural components, is similar to more familiar approaches for content analysis of qualitative data. Mishler (1986a) notes, however, that "the distinctive feature of narratives is that they refer to meaningful and coherent courses of action, with beginnings, middles, and ends" (p. 248), and this distinction is preserved when the narrative is analyzed as a narrative. In contrast to a content analysis in which sections of text are categorized and compared across informants to identify recurring themes, narrative analysis addresses substantial portions of a single text (or a whole text) as a unit. The sequential ordering of the data in the text is preserved in the structural analysis, and the relationships between segments of the narrative are explicitly addressed in the analysis of coherence that may be of interest to the researcher.

Because narrative constructions display the dynamic ordering of events, they are particularly significant in the construction of empirically grounded, dynamic theories of social processes (Mishler 1986a). There has been increasing research interest in developing such process models for IS development and implementation activities (Markus and Robey 1988; Newman and Noble 1990; Newman and Robey 1992; Sabherwal and Robey 1993). The narrative analysis approach presented here could inform the development and specification of social process models, particularly when data is collected primarily through retrospective interviews and the researcher must reconstruct events. A narrative analysis approach will not, of course, result in the one, "true" account of a project. Informants' narratives do not necessarily relate to real events and certainly relate them from the narrator's perspective (Mishler 1986b). Even when data from informants' narratives are triangulated with other data sources 
such as observational data or documentary evidence, differences in the interpretation of actions and events are possible. However, narrative analysis can provide detailed insights into individual informants' understanding of project events and highlight similarities and differences in interpretations among informants.

This approach was used here to examine social cognitive processes such as knowledge sharing and sensemaking in IS development. As noted in the methodology section, the interview data examined in this paper was drawn from a research project on social negotiations around IT requirements definition (Davidson 1996). One area of research results suggested that narrativizing their experiences with IS development projects was a critical sensemaking process for participants, that they developed their understanding of the project, their own and others' roles, and of requirements for the IT application being developed by constructing and maintaining a narrative account of the project's history. Individuals built and updated their narrative account by reflecting on events and actions and by discussing possible implications with other knowledgeable organization members. A shared narrative account evolved among individuals who had similar experiences with the project and who engaged in jointsensemaking activities through discussion and analysis of events. Shared aspects of the narrative account were evident in common elements of individuals' project history stories and in the "official story" 2 conveyed to newcomers to the project or to outsiders. To extend this research, the narrative analysis approach described here is being applied to further analyze how project participants used narratives to communicate and share assumptions about requirements for the IS application, to make sense of changes at GHI, and to understand the implications of change for IS requirements. Structural analysis of the narratives obtained through retrospective interviews highlights actions and events of interest, for example, change triggers that influenced stakeholders' interpretation of requirements. Comparing the analysis of informants' stories indicates points at which key stakeholders reached agreement about IS requirements or recognized differences in assumptions.

The analysis of narratives, aside from its value in IS research, has applications for IS practice. Tracking narratives and examining changes that occur over time is a viable way to examine meaning making and organizational learning (Tenkasi and Boland 1993). Examining evolving project history narratives could highlight how events have been interpreted or misinterpreted (from a given perspective) and what has been learned, or should be "unlearned" (again, from a given perspective) about a project experience. Comparing and contrasting narratives, and perhaps positing new narratives, could surface tacit assumptions about what is canonical and what is noncanonical in the IS development context. In this way, as Boland and Tenkasi

\footnotetext{
${ }^{2}$ Schank (1990) uses the term "official story" to denote the sanitized account sanctioned by those in authority. The term is used more broadly here to denote commonly accepted and shared accounts of key project events. These accounts may or may not be sanctioned by those in authority.
} 
suggest, narratives could serve as boundary objects among the diverse stakeholders who must collaborate to successfully develop or implement IS in organizations by promoting perspective taking and organizational learning.

\section{CONCLUSIONS}

Developing, implementing, and using information technology applications in organizations is a complex social activity. It is often characterized by ill-defined problems or vague goals, conflict and power struggles, and disruptions that result from pervasive organizational change. Narrativizing experience in such an organizational context is undoubtedly fundamental to sensemaking and social negotiations. Narrative analysis is an approach that can inform our understanding of these activities. However, applying narrative analytic approaches in IS research poses a number of challenges.

Narrative analysis is an interpretive endeavor in which the analyst draws on his or her familiarity with broad cultural knowledge and values in the analysis (Mishler 1986b; Polanyi 1989). Although interpretive research has been gaining legitimacy and acceptance in the world of IS research (Walsham 1995), researchers will be challenged with the question of how the validity of a narrative interpretation can be assessed. Mishler (1986b) suggests that the question of validity should become one of assessing the plausibility of the analyst's interpretations, compared to other possible interpretations. The researcher must carefully and explicitly detail the steps taken in data collection and analysis, paying particular attention to the researcher's influence on, and participation in, the creation of a narrative, to the selection (and exclusion) of materials for analysis, and to the researcher's theoretical orientation and assumptions which enter into the analysis.

Of course, these comments apply to any rigorous methodological approach to data analysis. However, narrative analysis poses particularly tough challenges. For example, the researcher must decide whether he or she assumes that "all telling" is narrative in form or that narratives are one of many forms for "telling" (Mishler 1986b). The answer to this question will guide decisions about how to identify and bound narratives within an interview text and will influence the interpretation that results. Rather than striving for the one correct interpretation, multiple interpretations are not only possible but desirable to enrich the understanding of possible meaning in the narrative. For critics and reviewers unfamiliar with narrative analysis, the explication of multiple interpretations may discredit all accounts. There are practical difficulties as well as theoretical and methodological issues. Data collected through research interviews is voluminous, and texts may contain many interwoven and partial stories. Analysis is a time-consuming process, and adequate presentation of results may require more space than in often allowed in publishing outlets such as conference proceedings and journals. Analyses which focus on small sample sizes to allow for these difficulties are likely to be criticized as being unrepresentative or idiosyncratic. 
Despite these challenges, narrative analysis holds the promise of informing our understanding of information systems development and use in an organizational context in unique and interesting ways. The analytical approach discussed in this paper suggests some ways in which these issues may be addressed and illustrates the insights that may be gained as a result.

\section{REFERENCES}

Agar, M., and Hobbs, J. (1982). Interpreting Discourse: Coherence and the Analysis of Ethnographic Interviews.” Discourse Processes, Volume 5, pp. 1-32.

Bansler, J., and Bødker, K. (1993). "A Reappraisal of Structured Analysis: Design in an Organizational Context." ACM Transactions on Information Systems, Volume 11, Number 2, pp. 165-193.

Bell, S. (1983). "Narratives of Health and Illness I: DES Daughters Tell Stories." Unpublished paper.

Boje, D. (1991). "The Storytelling Organization: A Study of Story Performance in an Office-Supply Firm." Administrative Science Quarterly, Volume 35, pp. 106126.

Boland, Jr., R., and Schultz, U. (1995). "From Work to Activity: Technology and the Narrative of Process." In W. Orlikowski, G. Walsham, M. Jones, and J. I. DeGross (Editors), Information Technology and Changes in Organizational Work. London: Chapman and Hall, pp. 308-324.

Boland, Jr., R., and Tenkasi, R. (1995). "Perspective Making and Perspective Taking in Communities of Knowing." Organization Science, Volume 6, Number 4, pp. 350-372.

Brown, J., and Duguid, P. (1991). "Organizational Learning and Communities-ofPractice: Toward a Unified View of Working, Learning, and Innovation." Organization Science, Volume 2, Number 1, pp. 40-57.

Bruner, J. (1986). Actual Minds, Possible Worlds. Cambridge, Massachusetts: Harvard University Press.

Bruner, J. (1990). Acts of Meaning. Cambridge, Massachusetts: Harvard University Press.

Clark, B. (1972). "The Organizational Saga in Higher Education.” Administrative Science Quarterly, Volume 17, pp. 178-184.

Davidson, E. (1996). Framing Information Systems Requirements: An Investigation of Social Cognitive Processes in Information Systems Delivery. Unpublished Ph.D. Dissertation, Massachusetts Institute of Technology.

Gabriel, Y. (1991). "Turning Facts into Stories and Stories into Facts: A Hermeneutic Exploration of Organizational Folklore." Human Relations. Volume 44, Number 8, pp. 857-875. 
Gergen, K., and Gergen, M. (1986). "Narrative Form and the Construction of Psychological Science." In T. Sarbin (Editor), Narrative Psychology: The Storied Nature of Human Conduct. New York: Praeger Publishers, pp. 22-44.

Hansen, C., and Kahnweiler, W. (1993). "Storytelling: An Instrument for Understanding the Dynamics of Corporate Relationships" Human Relations, Volume 46, Number 12, pp. 1391-1409.

Howard, G. (1991). "Culture Tales: A Narrative Approach to Thinking, CrossCultural Psychology, and Psychotherapy." American Psychologist, Volume 46, Number 3, pp. 187-197.

Labov, W. (1972). Language in the Inner City: Studies in the Black English Vernacular. Philadelphia: University of Pennsylvania Press.

Labov, W. (1982). "Speech Actions and Reactions in Personal Narrative." In D. Tannen (Editor), Analyzing Discourse: Text and Talk. Washington: Georgetown University Press.

Labov, W., and Waletzky, J. (1967). "Narrative Analysis: Oral Versions of Personal Experience." In J. Helms (Editor), Essays on the Verbal and Visual Arts. Seattle: University of Washington Press.

LeGuin, U. (1989). "Some Thoughts on Narrative." Dancing at the Edge of the World: Thoughts on Words, Women, Places. New York: Grove Press, pp. 37-45.

Markus, M. L., and Robey, D. (1988). "Information Technology and Organizational Change: Causal Structure in Theory and Research." Management Science, Volume 34, Number 5, pp. 583-598.

Martin, J.; Feldman, M.; Hatch, M.; and Sitkin, S. (1983). "The Uniqueness Paradox in Organizational Stories." Administrative Science Quarterly, Volume 28, pp. 438453.

Martin, J., and Meyerson, D. (1988). "Organizational Cultures and the Denial, Channeling, and Acknowledgment of Ambiguity." In L. Pondy, R. Boland Jr., and H. Thomas (Editors), Managing Ambiguity and Change. New York: Wiley, pp. 93-125.

McConkie, M., and Boss, W. (1986). “Organizational Stories: One Means of Moving the Informal Organization During Change Efforts." Public Administration Quarterly, Volume 10, Number 2, pp. 189-205.

Mishler, E. (1986a). "The Analysis of Interview-Narratives." In T. Sarbin (Editor), Narrative Psychology: The Storied Nature of Human Conduct. New York: Praeger Publishers, pp. 233-255.

Mishler, E. (1986b). Research Interviewing: Context and Narrative. Cambridge, Massachusetts: Harvard University Press.

Mitroff, I., and Kilmann, R. (1975). "Stories Managers Tell: A New Tool for Organizational Problem Solving." Management Review, Volume 64, Number 7, pp. 18 28.

Mumby, D. (1987). “The Political Function of Narrative in Organizations." Communication Monographs, Volume 54 (June), pp. 113-127. 
Newman, M., and Nobel, F. (1990). "User Involvement as an Interaction Process: A Case Study." Information Systems Research, Volume 1, Number 1, pp. 89-113. Newman, M., and Robey, D. (1992). "A Social Process Model of User-Analyst Relationships." MIS Quarterly, Volume 15, Number 2, pp. 249-266.

Paget, M. (1982). "Your Son is Cured Now; You May Take Him Home." Culture, Medicine and Psychiatry, Volume 6, pp. 237-259.

Paget, M. (1983). "Experience and Knowledge." Human Studies, Volume 6, Number 2, pp. 67-90.

Polanyi, L. (1989). Telling the American Story. Cambridge, Massachusetts: MIT Press.

Robinson, J., and Hawpe, L. (1986). "Narrative Thinking as a Heuristic Process." In T. Sarbin (Editor), Narrative Psychology: The Storied Nature of Human Conduct. New York: Praeger Publishers, pp. 111-125.

Sabherwal, R., and Robey, D. (1993). "An Empirical Taxonomy of Implementation Processes Based on Sequences of Events in Information System Development." Organization Science, Volume 4, Number 4, pp. 548-576.

Sarbin, T. (1986). "The Narrative as a Root Metaphor for Psychology." In T. Sarbin (Editor), Narrative Psychology: The Storied Nature of Human Conduct. New York: Praeger Publishers, pp. 3-21.

Schank, R. (1990). Tell Me a Story: A New Look at Real and Artificial Memory. New York: Schribner.

Tenkasi, R., and Boland, Jr., R. (1993). "Locating Meaning Making in Organizational Learning: The Narrative Basis of Cognition." Research in Organizational Change and Development, Volume 7, pp. 77-103.

Walsham, G. (1995). “The Emergence of Interpretivism in IS Research." Information Systems Research, Volume 6, Number 4, pp. 376-394.

Wilkins, A. (1984). "The Creation of Company Cultures: The Role of Stories and Human Resource Systems." Human Resource Management, Volume 23, Number 1, pp. 41-60.

\section{BIOGRAPHY}

Elizabeth J. Davidson is an Assistant Professor in the Department of Decision Sciences at the College of Business Administration of the University of Hawaii, Manoa. Her research has focused on investigations of social cognitive processes in the development and implementation of information technology applications in an organizational context. In recent work, she has examined the role of narratives and metaphors as sensemaking devices in requirements definition activities. Dr. Davidson received her Ph.D. in Information Technologies from the Sloan School of Business at MIT in 1996. 


\section{Appendix A \\ Text Segment from Interview with the INFOSYS Project Manager}

1 Q: So I guess what I'd like to do is just have you

2 tell me again

3 from your perspective

4 how the project got started

5 and how it relates to other things that have

6 happened in the company.

A: $O K[p]$ and going back to the very beginning?

Q: Yeah, and you don't necessarily have to go through a lot of the details.

12 I think Tim went through kind of the timing but, how it got started and why?

A: Rally, there have been several fits and tarts and [p] most distant one in my mempry is um [p] I was in the account reporting department and we were looking at providing accounts with some access that they could have to their own data. Um [p] you know, at that point there was a...a systems team that I managed and there were analysts that actually took the data that we produced and wrote the narrative that went along with the report, and that type of thing. And there were standard reports that went out to accounts.

26 And there are also special requests, ad-hoc kinds of 27 things that came in.

28 But the problem that we saw was that for some of 29 the major accounts, we had many people doing or 30 at least one dedicated person doing benefits design 31 type things. Um...that they would submit a

32 complicated request. It would go through the

33 marketing area, and the marketing area would come

34 to the analyst. The analyst would be interpreting

35 this request and then put in a data request to the

36 programmers. And the programmer would program

37 something, give it back to the analyst and the

38 analyst would write something up and then it

39 would go back to marketing and then finally back

40 to the account. What the account really requested

41 and what they received in the end, most of the time

42 either wasn't exactly the same or they realized that

43 yes, this is what they requested but it really wasn't

44 what they wanted underneath.

45 So there was a need identified to be able provide

46 accounts with some access to their own data.

47 And at that point um [p] there were few of us that

48 went around and looked at a different ... a couple of

49 different alternative ways of doing this.

50 And [p] in terms of, you know, the ... the build or

51 buy option, whatever.

52 You know, we had been building our own data

53 repository. But didn't, you know, have the friendly

54 front-end type thing.
55 So we had explored doing our own or um ... you

56 know, going with an outside vendor to do that.

57 We had interviewed several different companies.

58 One of the companies was INFOSYS.

59 And we had gone over to their office ...

60 and had seen the product, whatever.

$61 \mathrm{Um}$ [p] and it got to a certain point, and when it

62 started to get, you know, 'We did our analysis that

63 this is the company,' you know, 'We'd like to look

64 at this company more,' or whatever,

65 I think it kind of bumped up a couple of levels

66 and then came back down like, 'Well no, we really

67 don't want to do this at this point,'

68 and we kind of went 'bye.'

69 So I didn't here anything else about it for a while.

$70 \mathrm{Um}$ [p] a couple of years later um [p] well .. yeah,

71 after this time period, account reporting became

72 part of actuarial. Which was actuarial and

73 underwriting. And the analysts actually started to

74 report for the underwriters.

75 And, at that point we heard from RBC,

76 which is our major local account, that they were

77 interested in having this kind of capability in order

78 to look at their own data and do some analysis

79 themselves and that sort of thing.

80 And the marketing reps um .. who were RBC's,

81 started contacting different people in the actuarial

82 area and the IS area at that point;

83 there's no ISI at this point in time,

84 and saying 'Well gee, we should look at a few

85 vendors out there ... um...but they really seem to

86 like INFOSYS.'

87 So, a team that was at a higher level than myself

88 so I wasn't involved in the actual going around and

89 interviewing vendors at this point.

90 That was more Dave and um ... people at his level.

91 They went out and interviewed a few vendors and

92 figured out what was going on, whatever.

93 One of the major competitive vendors was a vendor

94 that RBC had already been doing business with and 95 wasn't too pleased with.

96 So it kind of came down to well, INFOSYS is the

97 best thing out there um .. at this point.

98 You know, maybe, they [RBC] really like it.

99 They've seen it and they really like it

100 and maybe we should look into INFOSYS

101 So at that point, a team was put together

102 of people from actuarial, underwriting, account

103 reporting, um ... and IS

104 to sort of, you know, look at this and negotiate a

105 contract and, you know, build a system and um ...

106 an interface to INFOSYS and all that.

107 And I was a part of that uh ... effort ... 


\section{Appendix B Text Segment from Interview with the INFOSYS Project Sponsor}

1 [Q]: A number of people have kind of told me the story about INFOSYS in that they said RBC was

3 looking at it. They contacted GHI. Is that how you 4 think the project got started?

\section{[A]: Yeah.}

We were, we had been talking for years about a data warehouse, an MIS system for, probably going on a decade pretty soon

10 and we were talking about it two and a half years ago 11 and some new people had been brought on and

12 MIS, before they were outsourced,

13 and INFOSYS was one of the, was something that

14 was looked at,

15 but not looked at seriously

16 and then RBC came along

17 and said, "We have looked at this. We want to

18 access our own data. We want you to give that to

19 us and oh, by the way, we looked at this product on

20 our own but it is too expensive for us to buy, but

21 we would like you to give it to us."

22 And there is, and we probably, we can give it to

23 them at a lesser cost than they could buy it

24 themselves, because buying it themselves was two

25 hundred thousand dollars a year, so it is very [p]
26 and I think that that is something that INFOSYS

27 recognizes and that's why they developed this an 28 insurance carrier system, knowing that it was 29 getting too expensive, for other than the biggest 30 accounts, to go out and provide this service to 31 individual accounts. If they sold it to carriers then 32 carriers could use it internally and also sub-license 33 it out to accounts. It would be another marketing 34 channel and if we do put it out on an account's 35 desktop, likely they will pay a sublicense fee to 36 INFOSYS so they still gain some income.

37 So, we looked at INFOSYS

38 and I and the IS people I was working with back at 39 the time saw it as a solution to the, a quicker 40 solution to the $\mathrm{RBC}$ issue and also a quick way to 41 jump us into having a management information 42 systems.

43 Although it wouldn't satisfy all of our needs, it 44 would satisfy the biggest area of demands, which 45 were claims, cost utilization reporting, enrollment 46 reporting,

47 so we saw it as, although an expensive way, a fast 48 way to jump start us into a management information 49 situation. 


\section{Appendix C \\ Text Segment from Interview with GHI Executive}

1 [Q]: I talked to almost thirty people or so on this project now and your name has started to come up with, "Sam was involved with that." Can you tell me just a little bit about what your, and how you were involved in this?

[A]: Sure. When I first came here back in '91, we had just completed some work with the Dryer poll people.

10 They do a survey every year and they look at the seventeen major factors that drive corporation's decisions around who to purchase health care from and one of the issues in the way and there's tons of issues, a lot of them around cost, as you know, network, quality of care, and you know, all that junk.

18 One of them was, especially for the self 19 insured customers, was account reporting, access to the information so that they know, on a fairly frequent basis, how well their health care provider is performing on their behalf, so that it is not a surprise once a year at renewal but there's a fairly consistent and current flow of information between health care providers and the buyer, and that came up as a very high need in almost all large companies during the Dryer survey and there is a moderate need in the middle size companies. It's kind of off the screen for small companies. First of all, most of them aren't self insured and second of all, they have got fairly standard products and they have fairly standard pricing.

So we said that,

oh, and the other data point was that there was nobody in the marketplace that did it well. Nobody.

Obviously, an opportunity for somebody to do it well.

So, I was part of a group of folks here, a group meaning, only two or three of us. We kind of did a quick look. What do we provide? $\mathrm{A}$, what do we have available for data that could drive a reporting capability that would get us to work [?fast] and quickly.

We didn't have anything.

We had some very old technology and large data bases that had questionable integrity and they were hard to get at.
53 INFOSYS, on the other hand, as a tool, has

54 been in the business for, I don't know,

55 fifteen years and their tool that does things

56 like account reporting which was the first

57 product we bought has the advantage of

58 having a lot of clinical knowledge and clinical

59 protocol built in, so there is a lot of stuff in

60 there that could, quote, interpret the data on

61 behalf of the viewer of the data. So, you are

62 not just getting raw data and you have to go

63 figure it out. They really give you a lot of

64 structured queries and reporting techniques

65 that allow you to analyze the data

66 and one of our biggest accounts, XYZ

67 and then RBC,

68 had expressed an interest in INFOSYS.

69 In fact, XYZ expressed the interest before I

70 got here.

71 They became so enamored with the tool that 72 they went out and bought it themselves, and 73 we were providing historical claim data for

$74 \mathrm{XYZ}$ so that they could do their own

75 reporting.

76 So we weren't even in the loop on that

77 and RBC went out and looked at it

78 and they wanted to acquire it but the

79 acquisition cost, they couldn't justify it. It

80 was something like three hundred thousand

81 for the license and they couldn't justify it

82 and they asked us if we would be interested

83 in acquiring it and letting them be the guinea

84 pig.

85 So, we took a look at it

86 and also Tom Smith [CEO] had had some

87 experience with it in [his previous position]

88 and he was very impressed with the product

89 so we kind of had an in house testimonial to

90 it.

91 We all looked at it

92 and they also had just announced the product

93 for the desktop of an account,

94 for an account to pull its own data right down

95 to its own PC and use PC based tools to do

96 its own reporting fairly quickly, easily and

97 much cheaper than doing it at the mainframe

98 level,

99 and so we went out and acquired the license

100 and it turned out we were either the second or

101 third largest company in the country to

102 acquire the license, to run the software

103 ourselves and to pull the data down to the

104 PCs for our accounts. 